\title{
O MITO DA UNIÃO NACIONAL: A CONSTRUÇÃO DAS "FAMÍLIAS BRASILEIRAS" NA DITADURA DO ESTADO NOVO
}

\author{
THE MYTH OF THE NATIONAL UNION: THE CONSTRUCTION OF \\ THE "BRAZILIAN FAMILIES" IN THE NEW STATE DICTATORSHIP
}

DOI: http//dx.doi.org/10.15448/2178-3748.2017.2.27448

Fábio Roberto Wilke

Mestre em História (Universidade Federal de Santa Maria)

wilkerf@gmail.com

\begin{abstract}
RESUMO: Este artigo procura estabelecer a relação entre mitologia política, através da construção de Getúlio Vargas como o "pai dos pobres", a questão da construção e solidificação da memória de determinado regime político, bem como a construção retórica por parte da política estado-novista em relação à família. Para isto, na primeira parte deste artigo se aborda o modo como o Estado Novo interferiu na família através de uma concepção pública, ou materializada, demonstrando ações efetivas do Estado em relação à família, notadamente através de políticas públicas que buscaram transformar a força de trabalho. Em um segundo momento, busca-se complementar este movimento, abordando modos em que o Estado Novo utilizou-se de uma ideia privada de família, ao se utilizar desta para a retórica política de união nacional através do trabalho, do mesmo modo que para a coação de setores sociais. Por fim, como se construiu, durante o Estado Novo, a mitologia política de Vargas como o "pai dos pobres" e qual o resultado disto no que se refere a construção de memória.
\end{abstract}

PALAVRAS-CHAVE: Ditadura do Estado Novo. Família. Política.

\begin{abstract}
This article tries to establish the relation between political mythology, through the construction of Getúlio Vargas as the "father of the poor", the question of the construction and solidification of the memory of a certain political regime, as well as the rhetorical construction by the state-new politics in Relation to the family. For this, the first part of this article addresses how the Estado Novo interfered in the family through a public, or materialized, conception, demonstrating effective actions of the State in relation to the family, notably through public policies that sought to transform the labor force. Secondly, it seeks to complement this movement, approaching ways in which the Estado Novo used a private idea of family, when using it for the political rhetoric of national union through work, in the same way as for the social sectors. Lastly, how Vargas's political mythology was constructed during the Estado Novo as the "father of the poor" and what the result of this is the construction of memory.
\end{abstract}

KEYWORDS: New State Dictatorship. Family. Politics.

Custosa é a tarefa de discorrer sobre o período histórico que abarcou os anos de 1930 a 1945, no Brasil, sem relacioná-lo às vultosas transformações políticas, econômicas e, sobretudo sociais, ocorridas. O contexto, caracterizou-se por uma reorganização das frações de classe que compunham o poder político no país, em uma disputa imbricada no seio do poder nacional 
envolvendo, como demonstra Boris Fausto, (2015, p. 186) grupos políticos estaduais, vencedores de 1930, além dos tenentes, e setores da Igreja Católica. Ao mesmo tempo em que o poder político hegemônico se recompôs, houve um particular e progressivo movimento de expansão burocrática, que visou dar capacidade de execução ao projeto político e econômico de poder em voga, como ressaltou Sérgio Miceli (1979).

Nesta elaboração, todavia, nos deteremos majoritariamente ao recorte espaço-temporal que teve início com o golpe de novembro de 1937, o qual deflagrou a Ditadura do Estado Novo, que se estendeu até o ano de 1945. Ditadura esta, que se distinguiu por aliar autoritarismo ${ }^{1}$ político e intensa perseguição política à construção da Legislação Trabalhista, movimento que pretendeu a normativa das relações entre capital e trabalho em categorias profissionais organizadas. A propósito, este foi um paradoxo significativo a ser contemplado, pois ao autoritarismo político promovido pela Ditadura do Estado Novo, conjunta e paradoxalmente, denotou-se uma série de transformações levadas a cabo pela burocracia estatal, que atingiram significativamente os setores sociais ligados ao mundo do trabalho, ao lado da intensa repressão a movimentos de oposição política.

Diante deste contexto estabelecido, este artigo pretende percorrer por algumas questões que possuem entre si a questão da família como eixo de ligação. Seja através da família considerada enquanto instituição social que foi alvo de ações políticas, visando ações sociais em relação a classe trabalhadora, seja através da família considerada como um conceito abstrato, que pôde ser utilizado para fins de retórica política do governo estado-novista.

Do mesmo modo, este foi um contexto no qual se percebeu a construção de uma mitologia política em torno do pressuposto de um novo Brasil. À ideia de formação de um novo país, centrado em uma nacionalidade vinculada fortemente a questão do trabalho, houve a adição de um ideário político, no qual a família ganhou relevo no que se referiu à retórica política. Ou seja, houve a percepção, por parte da política estado-novista, de que a família poderia constituir-se como um canal pertinente de ação política - material e simbólica. Para compreendermos a questão da mitologia política e também da família, nos filiamos a ideia estabelecida por Raoul Girardet (1987, p. 13), quando este estabelece que o processo de construção de um mito, ou de uma mitologia, permite além da explicação de determinada realidade, a própria mobilização dos elementos dispostos nesta. No caso brasileiro, esta questão

1Recente obra que percorre a questão do autoritarismo político durante o primeiro governo Vargas é a de SILVEIRA, Helder Gordim da. ABREU, Luciano Aronne de. (orgs). De Vargas aos militares: autoritarismo e desenvolvimento econômico no Brasil. Porto Alegre: Edipucrs, 2014. 
está relacionada tanto à busca de apoio à Ditadura, quanto da formação de uma mão de obra voltada a quesitos de ordem e cooperação política.

No que se refere à família, denotamos que a retórica política esteve voltada, por um lado, a ela enquanto instituição social, ancorada nos pressupostos de trabalho pretendidos, e como ambiente propício à formação e manutenção do trabalhador brasileiro. Por outro, à ideia de nação, no sentido de "família brasileira", noção que trazia consigo características de união, de unidade nacional - em detrimento de particularismos regionais - e trabalho conjunto. Não podemos desconsiderar, do mesmo modo, que foi neste momento que ocorreu o trabalho de construção de Getúlio Vargas como o "pai dos pobres", caricatura que percorre até os dias atuais, mesmo que sob crítica de parte da historiografia. Angela de Castro Gomes, complementa este cenário ao afirmar que:

Era o Estado, personificado na figura de Vargas, que possibilitaria o acesso dos trabalhadores aos instrumentos de realização individual ou social. Desde então, no Brasil, a relação homem do povo/Estado, fundou-se em grande medida, nessa mitologia do trabalhador e do trabalho como fonte de riqueza, felicidade e ordem social. (GOMES, 1999, P. 71)

Por outro lado, a questão da construção da memória também nos interessa. Regimes de exceção, assim como a Ditadura do Estado Novo, utilizaram historicamente este recurso enquanto ferramenta política. Podemos tomar como exemplo, os regimes fascistas europeus, na Itália e na Alemanha, onde a memória - voltada ao passado, mas também ao presente - serviu como instrumento político pertinente. No Brasil, tivemos a criação do Departamento de Imprensa e Propaganda (D.I.P.), órgão que possuiu importante função de propaganda bem como de censura. O D.I.P., além de seu trabalho com a censura de publicações que se opusessem ao Estado Novo, foi responsável por materiais de ode ao governo e a Vargas, como a cartilha "Getúlio Vargas o amigo das crianças", por exemplo, em 1940².

Sendo assim, a família se apresentou, no contex to de formação e consolidação do Estado Novo, como um instrumento importante no que se refere a construção política. Ao mesmo tempo, sua possibilidade diversa de abordagem a transforma em objeto proveitoso de pesquisa histórica. Neste sentido, levantaremos uma questão de análise a qual perseguimos, que é: de que modo compreender a ideia conjunta de família - pública e privada - construída durante o Estado Novo?

${ }^{2}$ Sobre a cartilha, acessar: $<<$ http://cpdoc.fgv.br/producao/dossies/AEraVargas1〉>. 
A retórica política desenvolvida por Getúlio Vargas e seu grupo político foi constituída, essencialmente, pelo recurso a união nacional. Esta união, que teria o trabalho como fio condutor, seria necessária para a definição dos pilares de sustentação da nova nação, pretendida desde o início dos anos 1930, e ratificada com o Golpe de 1937. Neste sentido, podemos avaliar esta questão, já nos primeiros discursos proferidos por Getúlio, como neste que apresentamos:

\begin{abstract}
A nova Constituição, colocando a realidade acima dos formalismos jurídicos, guarda fidelidade às nossas tradições e mantém a coesão nacional, com a paz necessária ao desenvolvimento orgânico de todas as energias do país. Os imperativos de ordem e segurança predominam. Garante o trabalho e o capital, a família e o Estado, as atividades produtivas e o funcionamento regular do poder público. (VARGAS, 1937, p. 114).
\end{abstract}

Ou seja, nas palavras de Vargas, esta "coesão nacional", estaria disposta a um pretexto fundamental. Garantir o "desenvolvimento orgânico de todas as energias do país". Em relação a isto, percebemos que se referiu ao funcionamento pleno das forças produtivas, elemento de transformação nacional. Da mesma forma, as análises dos discursos de Getúlio Vargas, durante os oito anos de Ditadura ${ }^{3}$, apontam para a construção retórica de certa coação que ligou os termos trabalho, família e nação (e seus análogos). Isto, pois o discurso de trabalho em prol da coletividade, avesso a individualismos, funcionou como uma permanente imposição aos trabalhadores.

Prosseguindo neste sentido, em um primeiro momento abordaremos a concepção de família a partir de uma lógica privada, ou particular. Esta ideia de família pode ser entendida como um grupo social composto por elementos que coabitavam um mesmo local, e que puderam ser alvo das ações de políticas públicas. Isto nos possibilitará, posteriormente, realizar a ligação com o ideal público de família, aquele ligado ao bem comum e, no período em questão, ligado ao ideal mais amplo de nação.

Feito isto, a junção destas concepções poderá nos propiciar uma proposição teórica mais ampla, que dialogue com o ideal de família proposto pela Ditadura do Estado Novo. Ideal que passou pela construção do discurso político através da elaboração do mito Getúlio Vargas e, da mesma forma, de memórias, haja vista o esforço institucional em solidificar não somente uma imagem de presente, mas também de futuro a ser alcançado, onde a Ditadura se apresentava como o único caminho possível.

\footnotetext{
${ }^{3}$ Discursos disponíveis na coleção “A nova política do Brasil”, que contém discursos de Getúlio Vargas décadas de 30 e 40.
} 


\section{As "famílias brasileiras": a família como ideia privada}

A necessidade de amparo a família foi recurso recorrente utilizado na retórica política do Estado Novo. Em 1934, pela primeira vez, tornou-se um dispositivo Constitucional isto, porque, o diagnóstico apontado por intelectuais e propositores políticos apontava para a necessidade de seu fortalecimento. De acordo com Poletti (2012, P. 16) o tema da família, assim como da educação e ordem econômica e social, foi posto ao cargo de José Américo, João Mangabeira e Oliveira Vianna nas discussões para elaboração dos dispositivos constitucionais. Ao Estado, por sua vez, ficaria o encargo de subsidiar este fortalecimento principalmente através das políticas públicas.

Aliado a isso, a ideia de que setores sociais viviam em condições de atraso civilizatório foi preponderante, e isto concorreria para o atraso do desenvolvimento nacional, que estaria ligado à precária situação geral da força de trabalho. Como ressalta Getúlio Vargas, em manifestação no ano de 1940, quando dizia que "relegados à existência vegetativa, privados de direitos e afastados dos benefícios da civilização, da cultura e do conforto, os trabalhadores brasileiros nunca obtiveram, sob os governos eleitorais, a menor proteção, o mais elementar amparo", contido em D'Araujo (2011, p. 394).

Foi neste ponto que a ideia privada de família ganhou destaque, ao tempo em que o reduto familiar passou a ser considerado, pelo Estado, como objeto a ser contemplado por suas intervenções. O meio familiar, e aqui o pensamos como um conjunto social que tem a habitação, os hábitos alimentares e higiênicos como um complexo, passou a ser visto como um meio pertinente de intervenção estatal. Neste sentido, o Censo Demográfico de 1940 observou como parâmetro para estabelecer seus levantamentos, o "domicílio". Este, foi compreendido como "o lugar onde mora uma pessoa que vive só ou em companhia de outras, residentes sob o mesmo teto ou em determinadas peças de um mesmo prédio, desde que esteja subordinado à responsabilidade, fiscalização ou direção de um chefe de família, gerente, administrador, etc." 4 Faz-se interessante denotar que, neste censo, são considerados chefes de família homens e mulheres, desde que responsáveis pelo sustento da família.

Estas medidas de intervenção social na família se tornaram relevantes, porque o trabalho, neste contexto, foi o condutor geral das proposições políticas e, através dele, se interligaram as ideias de nação, de prosperidade nacional e, em última instância, do próprio

\footnotetext{
${ }^{4}$ Ver: Instituto Brasileiro de Geografia e Estatística. Recenseamento Geral do Brasil. Serviço Gráfico do Instituto Brasileiro de Geografia e Estatística, 1950. p. 30.
} 
homem e cidadão. Neste sentido, a intervenção política efetiva em relação à família, deteve o propósito maior de construção do propagado progresso, através de um ideal amplo de trabalho.

Desta forma, a ação estatal no âmbito familiar extrapolou um sentido restrito de intervenção social, pois esteve ligada a uma concepção específica de desenvolvimento da nação e perpetuação de um sistema político, a Ditadura. Ora, de acordo com as proposições políticas do Estado Novo, para que as forças produtivas nacionais prosperassem, seria necessário não somente o fortalecimento dos trabalhadores atuais e a eventual "correção" de práticas consideradas não condizentes, mas, da mesma forma, que se fortalecesse e também aumentasse o número de futuros trabalhadores. Foi nesse sentido que ações ligadas às mulheres e as crianças, visando a melhoria de práticas de saúde e higiene, como os postos de puericultura, estiveram presentes. Não ao acaso, durante as décadas de 30 e 40, foram criados órgãos com o intuito específico de amparo, como o Departamento Nacional da Criança, em 1940, e o Conselho Nacional de Puericultura, em 1938.

Deste modo, a interferência política na família, em âmbito privado, se desenvolveu nestes termos, no sentido de amparar socialmente setores da sociedade que, às vistas da Ditadura, tinham algo a contribuir no que se referiu ao desenvolvimento das forças produtivas do país. Fortalecer a família, em âmbito privado, significou conformar a formação social de um modo geral, pois continha os trabalhadores, mas também as mulheres, aquelas pretensas responsáveis pela condução moral dos homens, e as crianças, a quem caberia o papel futuro de braços da nação. Neste sentido se referia Vargas (1938, p. 385), ao dissertar sobre a educação e ao amparo aos jovens, pois acreditava que "na formação da mocidade está o fundamento de uma política construtiva e dinâmica. A sua prática virá remover numerosos obstáculos que entorpecem o progresso nacional”.

Neste sentido, podemos interpretar a ideia privada de família relacionada a um pressuposto objetivo de família. Ou seja, ligada intimamente às políticas públicas, à intervenção estatal, às questões próximas e objetivas de desenvolvimento social e econômico pretendidos pelo Estado. Saneamento básico, habitação, alimentação, proteção às crianças recém-nascidas, salário, etc. O diagnóstico traçado pelo Estado Novo apontou, desde 1930, para a necessidade de alçar a família ao posto de dispositivo constitucional, o que foi inaugurado em 1934 e confirmado na Constituição outorgada de 1937. A partir disso, seria possível sua intervenção, no sentido de conformar hábitos e práticas não condizentes com os pressupostos de desenvolvimento que seriam alcançados através do trabalho. 
Ao mesmo tempo, esta ideia privada de família - pois se refere ao grupo social restrito - dialoga com o ideal público de família, ou abstrato. Pressupomos que esta interligação, entre um ideal privado e um público, tendo como fio condutor a questão mais ampla do trabalho, fortaleceu a retórica política dispendida a exaustão no Estado Novo. Esta retórica, buscou a criação de um novo país, ancorado em determinada moral conservadora, muito em parte influenciada pela doutrina católica e pelo desenvolvimento da força de trabalho.

A construção de determinada noção de união nacional, através da "família brasileira", serve como um pertinente exemplo do modo em que estas duas ideias podem ser articuladas. Vargas (1938, p. 387), ao inaugurar o prédio do Ministério do Trabalho, Indústria e Comércio, em 1938, exprimia que "foi sempre elevado o meu juízo sobre vossas reservas de energia patriótica, inteireza moral e devotamento ao bem público, dentro da ordem, para o maior bem da família brasileira e tranquilidade do trabalho, criador de fartura e propulsor de aperfeiçoamento cultural".

Sendo assim, passaremos à análise da família construída pela retórica estado-novista como uma acepção pública. Esta, ligada aos pressupostos mais gerais de nação, se afirmou no sentido de possibilitar a "coesão nacional" pretendida por Getúlio Vargas, através da unificação da "família brasileira".

\section{As "famílias brasileiras": a família como ideia pública}

Prosseguindo em nossa argumentação, nos deteremos à noção complementar e articulada de família que estamos propondo. Ou seja, a família enquanto ideia pública. Quando nos referimos a isso, a pensamos conjugada à retórica política do Estado Novo. Esta, através das manifestações tanto de Getúlio Vargas, bem como de seu ministro do trabalho, Marcondes Filho, identificou a formação social brasileira de acordo com uma significação mais ampla de nação, a "família brasileira".

Getúlio Vargas desenvolveu uma escalada autoritária durante os anos de 1930 e 1945, tendo como expoente de suas ações antidemocráticas, o golpe de novembro de 1937, que inaugurou a Ditadura do Estado Novo. Estas ações, de acordo com o ideal autoritário absorvido por seu grupo hegemônico e influenciados por intelectuais como Oliveira Vianna e Azevedo Amaral, dentre outros, se apresentavam necessárias ao desenvolvimento de um novo país, ancorado na moral do trabalho e na riqueza - material e espiritual - que o desenvolvimento das forças produtivas poderia trazer consigo. 
Ou seja, mesmo que alheias às convenções democráticas, as intervenções políticas do Estado Novo se pressupunham "legítimas", por capitanear as mudanças rumo a uma nova organização social. Para isso, o apelo a "unidade nacional", a "coesão das forças orgânicas", entre outros dispositivos retóricos, se fizeram recorrentes nos discursos de Getúlio Vargas. Neste sentido é que a ideia pública de família ganha força, pois ela seria capaz de realizar a junção desde a concepção privada de família, até o ideal geral de nação, traduzido a partir do slogan "família brasileira".

Por outro lado, o Estado Novo demonstrou intensa perseguição aos seus opositores políticos, elegendo os comunistas como o seu principal inimigo. Em uma época onde a doutrina católica detinha influência considerável em círculos intelectuais e políticos, o Estado Novo absorveu alguns de seus pressupostos, acusando os comunistas de colocarem em perigo a doutrina de "Deus, pátria e família". Neste sentido, Vargas pregava a necessidade do combate aos propósitos comunistas no país, pois estes viriam com o intuito de fazer ruir as tradições, e dizia que:

Para combatê-los, é indispensável a união dos brasileiros de todas as camadas sociais e de todos os matizes políticos, antepondo uma muralha intransponível na onda dissolvente que pretende destruir os nossos lares e aniquilar, como patrimônio material e espiritual dos nossos maiores, o próprio futuro dos nossos filhos. (VARGAS, 1936, p. 68)

Faz-se importante denotar que é preciso que se entenda o conceito de "família" em um escopo abrangente de sentido. Com isso, queremos dizer que esta sugerida ideia pública de família não se manifestou apenas quando o discurso político a invocou literalmente, mas que esteve presente em temáticas diversas, porém análogas, como casa, habitação, lar, filhos, etc. Somente desta forma se pode perceber a amplitude deste discurso, que foi capaz de criar ao mesmo tempo um clima de coação, visto que não seria plausível o trabalho que concorresse contra à "sua família", e outra de busca de coesão.

Esta característica, da mesma forma, se demonstrou presente em pronunciamento de Getúlio, para o dia $1^{\circ}$ de maio de 1940 , no qual anunciou novas medidas na política trabalhista e dentro destas, a lei que instituiu a fixação do salário mínimo:

Procuramos, por esse meio, assegurar ao trabalhador remuneração equitativa, capaz de proporcionar-lhe o indispensável para o sustento próprio e da família. O estabelecimento de um padrão mínimo de vida para a grande maioria da população, aumentando, no decorrer do tempo, os índices de saúde e produtividade, auxiliará a solução de importantes problemas que retardam a marcha do nosso progresso. (VARGAS, p. 293, 1940). 
Neste exemplo, podemos perceber o tom empregado por Getúlio Vargas em seus discursos, de modo geral. A lógica de seus enunciados progredia para um sentido de homogeneidade, de busca de determinada coesão nacional em busca do desenvolvimento econômico comum. Não ao acaso ele celebra a "marcha do nosso progresso", que seria alcançada devido à implementação do salário mínimo, esforço coletivo que traria consigo a capacidade de estabelecer um "padrão mínimo" de vida para a população, mas sem perder de vistas o fato de que aumentaria, com o decorrer do tempo, os "índices de saúde e produtividade".

$\mathrm{Ou}$ seja, as ações políticas pretendidas pelo Estado estiveram associadas ao desenvolvimento amplo e conjunto da nacionalidade, através das benesses que o desenvolvimento do trabalho supostamente traria consigo ${ }^{5}$. Na verdade, para além de um sentido de nacionalidade, o próprio desenvolvimento econômico do país, através do desenvolvimento da força de trabalho, diagnosticada como apresentando, no período, deficiências que figuravam da ordem material até mesmo questões de saúde e alimentação.

É de acordo com esta percepção que Angela de Castro Gomes (1999) desenvolve sua argumentação. De acordo com Gomes, para as forças políticas do Estado Novo, a família transformara-se em um canal eficiente de ligação entre o específico e o geral, o particular e o coletivo. As ações do Estado, traduzidas através das políticas públicas, ocorreram no sentido de fortalecer o trabalhador brasileiro, propiciando, deste modo, que a "marcha para o progresso" se desenvolvesse do modo pretendido. Assim, Gomes (1999, p. 6) assinala que "era pela família que o Estado chegava ao homem e este chegava ao Estado. Ela era a célula política primária, o leitmotiv do esforço individual dos indivíduos".

Quando nos referimos à ligação entre o específico e o geral, estamos sublinhando que a Ditadura do Estado Novo soube realizar a junção entre um significado simbólico e um material, objetivo de família, ao trabalhá-la em dois aspectos: por um lado, a família material, alvo das políticas públicas, seio da classe trabalhadora e das forças produtivas; por outro, a família das retóricas políticas, representando a "família brasileira" e a união nacional.

Como percebeu Angela de Castro Gomes, quando discorreu sobre as ações do governo de Getúlio Vargas, para o ano de 1942:

5 Neste sentido Angela de Castro Gomes (1999), a partir de Severino Sombra, desenvolve a ideia de "concepção totalista de trabalho" que seria o tipo de abordagem realizada pela equipe política do Estado Novo em relação ao trabalho. De acordo com esta concepção "totalista" seria necessário abordar o trabalho não somente em seus aspectos trabalhistas, propriamente, mas também em questões como saúde, alimentação, habitação, entre outros. 
Ainda antes do término do ano de 1942, em dezembro, o governo federal noticiou a criação do Serviço de Subsistência, cujo objetivo era oferecer mercadorias abaixo do preço de mercado às famílias trabalhadoras, ultrapassando as fronteiras da fábrica como espaço de ação educativa, na medida em que chegava a casa e família operárias. Assim, segundo os termos da propaganda estado-novista, Vargas estaria fazendo do Brasil "um lar imenso", e do Estado, um "Estado-Previdência". (GOMES, p. 62, 1999).

Não podemos deixar de ressaltar o fato da salutar a atuação de um dos principais departamentos do período, o Departamento de Imprensa e Propaganda, o D.I.P., fundado em 1939, a partir dos desdobramentos de outros órgãos de propaganda. Sendo assim, houve um trabalho conjunto que procurou estabelecer a ideia do Brasil enquanto um "lar imenso", sugerindo que a "nação brasileira" deveria reunir suas forças, por fazer parte de uma única "família brasileira" afastando, assim, possíveis dissensões. Com esta finalidade discursava o ministro do trabalho Marcondes Filho (1943, p. 28), ao dizer aos trabalhadores que "quaisquer que sejam os nossos intentos, as nossas funções, os nossos objetivos, o pensamento pela Nação deve estar presente em nosso dia, como se fora um instinto, como se fora um sexto sentido".

Desta forma, se denota uma dupla atuação que concorre nesta lógica. Por um lado, as ações efetivas dos Ministérios e Departamentos através dos Decretos-Lei, atuando materialmente a partir da promoção de políticas públicas variadas de amparo às famílias dos trabalhadores. Por outro, a atuação do Departamento de Imprensa e Propaganda em diversas esferas sociais, promovendo a ideia de Getúlio Vargas como o "pai da nação", como bem nos demonstra Oliveira (2001).

Sendo assim, tentamos formular uma concepção que uniu duas concepções distintas, porém complementares, de família. Por um lado, aquela ligada ao âmbito privado, particular. Por outro, uma ideia geral, ligada à concepção de nação pretendida pela Ditadura do Estado Novo.

Postulamos que a retórica política do Estado Novo lançou mão desses dois sentidos, utilizando-os de modo conjunto, de acordo com sua pretensão. De uma forma, referindo-se as suas ações práticas, de intervenção social, que visavam à conformação de setores da formação social e também a promoção de melhores condições de vida, tendo em vista a formação e manutenção de uma mão de obra assalariada capaz de manter o padrão de desenvolvimento pretendido. De outra, quando se referia à nação, à nacionalidade, à construção de um novo país. Isto propiciou certa unidade discursiva, dando coesão ao discurso de unidade nacional tão proferido por Getúlio Vargas. 
Realizar a comunhão entre estes dois aspectos de família possibilitou o estabelecimento de um fio condutor, que realizou a ligação desde a casa do trabalhador, até a nação, do indivíduo à formação social. A prática discursiva da política estado-novista foi audaz neste sentido, pois ao utilizar-se da família enquanto significado político, pôde construir um clima de suspeição, visto que quaisquer ações que pudessem ser consideradas de cunho individualista ou, por outro lado, de oposição, poderiam pressupor crime contra a própria nação. Marcondes Filho se expressava nessa linha, no ano de 1943, no programa de rádio "A hora do Brasil”":

Sei que não é só para o trabalho que o proletário vive, mas para o bem-estar da família, a tranquilidade da velhice e o futuro dos filhos - que é o seu pensamento pelo lar - e, ao mesmo tempo, para aumentar a própria eficácia, ter consciência das suas obrigações e cumpri-las integralmente que deve ser o seu pensamento pela Nação. (MARCONDES FILHO, 1943, p. 18)

Diante desse contexto, nos permitimos avançar à próxima questão, que compreendida em conjunto com o que propomos acima, realizará a síntese de nossa proposição geral. Tratase da construção de uma mitologia política ao redor da figura de Getúlio Vargas e, ao mesmo tempo, a solidificação de uma memória social referente ao Estado Novo.

\section{"Trabalhadores do Brasil": mito político e a construção da memória}

"A retórica nacionalista certamente não desapareceu, mas divide cada vez mais a cena com outras línguas da identidade coletiva". É com esta afirmação, dentre outras, que Jay Winter (2006, p. 70) inicia sua reflexão, em artigo onde discorre sobre a relação entre memória e política. Caso estivesse se referindo ao período que abarca os oito anos de hegemonia política de Vargas, à frente da Ditadura do Estado Novo, Jay Winter estaria equivocado, pois este foi um contexto com feições eminentemente nacionalistas e, no debate público, as questões de identidade coletiva estiveram restritas a grupos organizados de trabalhadores e imigrantes, mesmo que em um ambiente dinâmico.

Em tempos atuais, consideramos que aquilo que Pierre Nora (1993, p. 8) denominou de o "fim das sociedades-memória"6, se apresenta como uma realidade plausível. Isto seria o resultado de certa dilatação temporal, causada pelas intensas perturbações sociais e políticas

\footnotetext{
6 Nesta mesma passagem, Pierre Nora destaca o fim das "ideologias-memórias". A nosso ver, Nora se equivoca ao ligar a "ideologia-memória" somente à construção de memórias nacionais e, também, nos parece a de utopias sociais. Por outro lado, é preciso perceber que se de fato há o desmantelamento dessas ideologias durante o século XX há, da mesma forma, a consolidação do modo de produção capitalista em escala global, o qual também é produtor de ideologia. Se não mais aquela que assegura a transição do passado para o futuro, aquela que assegura um "presenteísmo" temporal.
} 
ocorridas, sobretudo, ao transcorrer do século XX. Neste sentido, Nora (1993, p. 12), afirma que neste traçado do século XX "a nação não é mais o quadro unitário que encerrava a consciência da coletividade (...)". A transição do século XX para o XXI se fez sob importantes transformações de ordem econômica e política, sobretudo trazendo consigo a memória ${ }^{7}$ de todas as sevícias ocorridas nos conflitos armados de amplitude mundial. Ao mesmo tempo, as identidades se fortaleceram, preenchendo um espaço que por décadas foi ocupado pelo ideal do Estado-nação. Não à toa emergem os conceitos como identidade coletiva (CASTELLS, 1999) e mesmo memória coletiva (HALBWACHS, 2006).

De outro modo, o contexto histórico do Estado Novo nos aponta para um cenário diverso. Este foi um período de intensa propaganda nacionalista, voltada à construção de uma nacionalidade caldada sob os pressupostos do trabalho. A Ditadura do Estado Novo, a partir de 1937, lançou mão de um sem-fim de instrumentos políticos de coerção social. Aqui, devemos pensar não somente dispositivos de repressão, ligados ao embate direto e violento. Da mesma forma, a propaganda e a construção de uma história e uma memória nacional e, sobretudo, o vislumbre de um futuro a ser perseguido, podem ser analisados sob este mesmo aspecto. Isto, porque o ideal de nação pretendido durante o Estado Novo, significou a coerção e a conformação de contingentes expressivos da formação social, de modo geral, e da classe trabalhadora, em particular. O indivíduo, nestes tempos, deveria estar subsumido à ideia geral de nação, não esqueçamos a intensa crítica ao Liberalismo que se difundiu durante os anos 30, acusando-o tanto pela desorganização contraproducente da economia nacional, bem como pela propagação de pressupostos desagregadores e individualistas no que se refere às relações sociais.

Ao nos referirmos a construção de uma história e uma memória nacional, queremos ressaltar que se constituiu uma narrativa em que o passado, composto por incompreensões de ordem política e incapacidades justificaria as ações presentes. Seria a legitimação histórica do presente, através de um passado que se pretendeu reconstruir, através da apresentação do Estado Novo como o modelo de organização política unicamente possível. Como nos auxilia Raoul Girardet (1987, p. 13), ao dizer que "o mito conta como uma realidade chegou a existência, quer seja a realidade total (...) ou apenas um fragmento". Assim, o Estado Novo se apresentou como uma solução evidente em um processo irrefreável de transformações.

7 Compartilhamos da análise de Jöel Candau (2014) sobre memória coletiva. Este realiza uma leitura crítica relativa ao conceito de "memória coletiva", sobretudo nos termos utilizados por Maurice Hallbwacs. Candau, afirma que, de fato, existem memórias coletivas, pois não há como encerrar certo tipo de unidade ou homogeneidade de memória mesmo em grupos relativamente pequenos. 
Da mesma forma, não podemos desprezar a influência da concepção corporativista, a qual buscou o almejado "apaziguamento das classes", através de uma pretendida conciliação entre os componentes do sistema produtivo, ou seja, os trabalhadores e os detentores dos meios de produção. Assim, se expressava Vargas, 1938, aos trabalhadores aglomerados na avenida São João, em São Paulo:

O Estado não conhece direitos de indivíduos contra a coletividade. Os indivíduos não têm direitos, têm deveres! Os direitos pertencem à coletividade. O Estado, sobrepondo-se à luta de interesses, garante só os direitos da coletividade e faz cumprir os deveres para com ela. O Estado não quer, não reconhece luta de classe. As leis trabalhistas são leis de harmonia social. (VARGAS, 1938, p. 311)

Ao Estado, nessa concepção, caberia expurgar os conflitos que a luta de classes traria, ele deveria servir, de certo modo, como um guardião da coletividade nacional. Para isto, não bastariam ações no sentido da tradução material de união ou igualdade coletiva, através das políticas públicas, por exemplo. Seria necessário o apelo à propaganda política, traduzida na personificação do regime na pessoa de Getúlio Vargas, ao mesmo tempo em que se traduziam os anseios particulares de um grupo político hegemônico como se fossem o anseio geral da nação. Foi justamente neste sentido que se fortaleceu o trabalho de construção de Getúlio Vargas como o "pai da nação" (Oliveira, 2001), ou da "família brasileira", por um lado e, por outro, a consolidação da Ditadura do Estado Novo como um regime de exceção que se justificaria pelo atraso econômico do país.

Roland Barthes (2009, p. 218) dirá que “o mito é uma fala roubada e restituída. Simplesmente, a fala que se restitui não é exatamente a mesma que foi roubada: trazida de volta, não foi colocada no seu lugar exato". O que se percebe é que Vargas, ao transferir para si a arena das ações políticas, e para a nação e a paz entre as classes o destino do desenvolvimento, realizou justamente um deslocamento da fala. A ambição por mudanças de cunho estrutural foi um discurso presente na disputa política e social de modo mais enfático desde, ao menos, a década de 1920. O Estado Novo procurou, dessa forma, demover a vanguarda de ação tanto de grupos organizados ligados aos trabalhadores como de grupos ligados ao capital, representantes de um liberalismo mais feroz.

A Ditadura do Estado Novo se sobressaiu pela intensa articulação entre política e propaganda. O Golpe de 1937 veio com o intuito de assegurar o processo de desenvolvimento das forças produtivas nacionais em um padrão capitalista estimado (FONSECA, 1989). Para, 
além disso, se propôs o regime enquanto o dirigente da elevação moral da população. $\mathrm{O}$ trabalho, neste sentido, serviria como uma ação redentora.

Se por um lado seria o responsável pelo crescimento da riqueza material da nação, por outro, seria o responsável por inculcar uma ética de valores em comum, que se desenvolveriam de acordo com os interesses da coletividade, pois como sugeriu Antonio Gramsci (1991, p. 33), a instituição de regimes políticos nos estados modernos está ligada substancialmente a estruturação de uma hegemonia ético-política, não somente econômica. Ao mesmo tempo se construiu, e aqui principalmente pelas ações do já referido D.I.P., o mito de Getúlio Vargas como o saneador dos problemas nacionais. Este viria para estabelecer a paz entre as classes, a harmonia dos lares, o desenvolvimento do país. Como bem denota Mônica Pimenta Velloso ao se referir da construção do mito Vargas:

O mito Vargas constrói-se à base de um múltiplo jogo de imagens que o mostram ora como homem comum, identificado com o povo, ora como político eficiente, realizador de inúmeras reformas na ordem social, ora como verdadeiro líder, investido de dotes especiais. Como homem é "cordato", "ponderado", "sensível", "pacificador" (...) como político é o "pai dos pobres", o "reformador", por excelência no campo do direito protegendo a família, "doando" a legislação trabalhista (...). Como líder, é "o estadista que prevê o futuro", o "homem providencial" que exerce efeito terapêutico sobre as massas. O chefe Vargas ainda é visto como exemplo a ser seguido pela nova geração. (VELLOSO, p. 85:86, 1982).

Dessa forma, Velloso nos demonstra como se desenvolveu o trabalho de construção da mitologia política ao redor de Getúlio Vargas. Algo a sublinhar, é que o Estado Novo deteve seus pressupostos políticos ligados fortemente ao presente, pois seria preciso o desenvolvimento imediato das forças produtivas. Não se faz ao acaso o apelo a ideais de união, de organicidade, de coesão, principalmente através daquilo que estamos defendendo nesta elaboração, da família.

O recurso retórico que aliou a ideia de família e privada, funcionou como um fio de ligação para um entendimento maior, qual seja o propósito de nação ou unidade nacional, a "família brasileira". Do mesmo modo, esta imagem de "família brasileira" esteve intimamente ligada aos pressupostos de trabalho, como se percebe neste discurso que D'Araújo (2011, p. 395) selecionou de Vargas, em 1940, quando ao se referir às ações do Estado, criou um ambiente de proximidade, como se estivesse cuidando mesmo da família do operário, e ressaltou que "a ação tutelar e previdente do Estado patenteia-se, de modo constante, na solicitude com que cria os serviços de proteção ao lar operário, de assistência à infância, de alimentação saudável e barata, de postos de saúde, de creches e maternidades (...)”. 
Porém, ao mesmo tempo em que houve a formulação ligada ao presente, ocorreu a elaboração tendo em vista o futuro, pois se a busca pelo desenvolvimento material e espiritual - e dentro disto a própria manutenção da Ditadura - se daria no presente, seria preciso também o estabelecimento de sua continuidade, e isto seria possível pela solidificação de uma memória construída desde o presente. Esta, possibilitaria a criação de um nexo entre um presente a ser construído e um futuro a ser alcançado. Para, além disso, se buscou construir uma elaboração que justificasse as ações do presente no presente, mas também no futuro. Deste modo Velloso discorre:

Reafirma- se, assim, o caráter "atemporal" do mito, sua transcendência em relação ao presente, que é apenas momento, parte, contingência. E neste esforço para transcender o tempo, a matéria, o concreto, a espiritualidade ganha novas dimensões. Neste sentido, importa mais que o nome do líder fique na memória afetiva do que nos retratos, importa mais que fique nos lábios do povo do que no nome das ruas. Busca-se, portanto, espiritualizar e/ou imortalizar sua memória, resgatando-a da materialidade "indigna" dos fatos. (VELLOSO, p. 97, 1982).

Ou seja, a construção de um mito, e neste caso um mito político, se desenvolve para que as ações do presente se tornem atemporais. A atemporalidade traz consigo a característica de homogeneizar, desde o presente, visando o futuro, questões que, ao seu tempo, poderiam apresentar pertinência. Barthes (2009, p.234), entende que "a função do mito é transformar uma intenção histórica em natureza, uma eventualidade em eternidade". O Estado Novo, nesse sentido, buscou se demonstrar enquanto a única opção realizável para o presente, ao tempo em que se afirmava como o futuro a ser vislumbrado.

Deste modo, a construção do mito se refere, supomos, à tentativa de apaziguar as tormentas do passado ou também justificar ações do presente para a posteridade. Ao certo a questão da criação do mito Getúlio Vargas é complexa, pois exibe a particularidade de uma construção ao tempo mesmo de vida do objeto. Todavia, esta é uma característica que, ao longo do século XX, se demonstrou em sistemas políticos diversos, principalmente nos regimes fascistas da Europa da primeira metade do século XX.

A Ditadura do Estado Novo, neste sentido, trabalhou intensamente para a promoção e justificativa de suas ações. Lembremos que Getúlio Vargas, em 1930 e 1937, alçou-se ao poder através de dois golpes armados. Seus discursos políticos estavam afinados com a ideia que todas as ações pretendidas e desenvolvidas autoritariamente se justificariam pelo atraso histórico do país e a necessidade que se impunha de intervenções radicais. 
Para além disso, as manifestações de Vargas e de seu grupo político apontavam o Estado Novo como a única opção para o Brasil, pois a outra estaria representada no "caos" e na “desordem" dos ideais comunistas. Como indica Jean-Pierre Sironneau (1985, p. 262) o mito apresenta uma "função sociológica, de legitimação da ordem social. O mito serve para unificar as crenças de um grupo, para legitimar o poder dos que dominam, assegurando a integração social". Se pode avaliar em que medida o mito possuiria a capacidade de apaziguamento, mas o que nos importa nessa reflexão é denotar, antes de tudo, sua intenção.

O Estado Novo utilizou-se, diuturnamente, daquilo que Pierre Nora (p. 12, 1993) denominou de "vigilância comemorativa". Concordamos com Nora quando este afirmou que "sem vigilância comemorativa, a história depressa os varreria (...) mas se o que eles defendem não estivesse ameaçado, não se teria, tampouco, a necessidade de construí-los". Não se fez à toa a repressão aos movimentos opositores e o total fechamento do sistema político a partir de 1937. Do mesmo modo, entendemos que esta percepção teórica de Nora pode ser apreendida tanto para a vigilância comemorativa que se refere ao presente em relação ao passado, como quanto para a construção do presente visando a posterioridade.

As comemorações cívicas do Estado Novo, como as de $1^{\circ}$ de Maio, que chegaram a lotar estádios de futebol, buscaram essa vigilância. Entretanto, é neste momento em que a História, enquanto aquela que desnaturaliza as aparências, age. Assim, Jacy Alves de Seixas (2001, p. 41), dirá que "a memória encontra-se, assim, prisioneira da história ou encurralada nos domínios do privado e do íntimo, transformou-se em objeto e trama da história, em memória historicizada". Isso, pois essas ações não passaram de uma ação presente, transformada em memória, muito em parte, pela história construída desde o presente.

Não há como apagar os elementos autoritários e ditatoriais que permearam as primeiras décadas de poder deste grupo político. Torturas, assassinatos, prisões, censuras, fizeram parte do cotidiano do poder principalmente após 1937. Ao mesmo tempo, restou intrigante como parcelas significativas da formação social pareceram consentir com isso.

Esta é uma afirmação delicada, mas que deve ser postulada se quisermos compreender como um governo autoritário e, após ditatorial, se manteve por tantos anos. Ao mesmo tempo, dentro daquilo que Pierre Nora (1993) denominou de "vigilância comemorativa", podemos perceber a intensa preocupação, pelo Estado Novo, em demonstrar os feitos e os avanços nas áreas sociais e econômicas.

Como se resolveria esta equação diante das práticas autoritárias? Sabemos que o recurso retórico do "bem maior" a ser buscado foi uma constante em regimes autoritários e, no Estado 
Novo, não se fez diferente. O que nos intriga é esta memória que se consolidou em torno de Getúlio Vargas como um grande estadista, e que desvanece, muitas vezes, suas passagens pelo poder onde lançou mão de franco autoritarismo e, de 1937 a 1945, de uma Ditadura.

Roland Barthes (2009, p. 235), dirá que “o mito não nega as coisas; a sua função é, pelo contrário, falar delas; simplesmente purifica-as, inocenta-as, fundamenta-as em natureza e eternidade, dá-lhes uma clareza, não de explicação, mas de constatação". Neste ponto, compreendemos que este é, de fato, a própria razão de ser do mito. Todavia, a História e a sua absorção da memória enquanto objeto não pode se abster desta problemática, pois a memória de um passado presente, diz respeito ao próprio entendimento do presente que se desenvolve.

É diante disso que a preocupação de Jeanne Marie Gagnebin (2006, P. 39) surge como um questionamento latente. A tríade verdade, memória e passado se articula proveitosamente no sentido de nos inculcar algumas perguntas relevantes. Como um regime ditatorial conseguiu transferir-se à posteridade de modo inegavelmente atenuado, ao menos no que se refere à percepção popular? Ao mesmo tempo, a busca por qual verdade, por parte da historiografia, tornou possível a manutenção desta memória?

Seixas (2001, p. 42), compreende que " a memória e o esquecimento aqui também só existem sob os olhares da história, investindo-se na reconstrução de novas identidades, a partir de um critério utilitário-político”. Após, ao trazer a consideração de Patrick J. Geray, Seixas (2001, p. 42) dirá que "toda memória, seja ela "individual”, “coletiva", ou "histórica", é uma memória para qualquer coisa, e não se pode ignorar esta finalidade política (no sentido amplo do termo)". Esta é uma questão que a história deve responder, ao se questionar a quem, afinal, esta "memória atenuada" da Ditadura Varguista beneficia.

A Ditadura do Estado Novo foi estabelecida com a autoproclamada missão de sanear os problemas sociais e econômicos do país. Para isso, vislumbrou a criação de uma nova ética nacional, ancorada no desenvolvimento das forças produtivas e da coletividade em detrimento de individualismos. Ao mesmo tempo, lançou mão, abertamente, de dispositivos autoritários e ditatoriais para o alcance de suas pretensões. Por outro lado, a construção da mitologia de Getúlio Vargas, o pai dos pobres", parece ter alcançado seu propósito. Diante disso nos resta a hesitação, de acordo com Gagnebin (p.41, 2006), em afirmar se a resposta de nossa questão pode ser buscada pela via do esquecimento ou da denegação da memória histórica.

\section{Referências bibliográficas}

BARTHES, Roland. Mitologias. São Paulo: Difel, 1982. 
CANDAU, Jöel. Memória e identidade. São Paulo: Contexto, 2014.

CASTELLS, Manuel. O poder da identidade. São Paulo: Ed. Paz e Terra, 1999.

D’ARAÚJO, Maria Celina de. Getúlio Vargas. Brasília: Câmara dos Deputados, Edições Câmara, 2011.

DE OSTOS, Natascha Stefania Carvalho. Terra Adorada, Mãe Gentil: representações do feminino e da natureza no Brasil da Era Vargas (1930-1945). UFMG, 2009.

FAUSTO, Boris. História Concisa do Brasil. São Paulo: Editora da Universidade de São Paulo, 2015.

FONSECA, Pedro Cezar Dutra. Vargas: o capitalismo em construção - 1906-1954. São Paulo: Brasiliense, 1989.

GAGNEBIN, Jeanne-Marie. Verdade e memória do passado. Memória, história, testemunho. In: Lembrar, escrever, esquecer. São Paul: Editora 34, 2006.

GIRARDET, Raoul. Mitos e mitologias políticas. São Paulo: Companhia das Letras, 1987.

GOMES, Angela de Castro. Ideologia e trabalho no Estado Novo. In. PANDOLFI, Dulce (Org.). Repensando o Estado Novo. Rio de Janeiro: Ed. da Fundação Getúlio Vargas, 1999.

GRAMSCI, A. Maquiavel: a política e o Estado Moderno. $8^{\text {a }}$ Ed. Rio de Janeiro: Civilização Brasileira, 1991.

HALBWACHS, Maurice. A Memória Coletiva. São Paulo, Centauro: 2006.

INSTITUTO BRASILEIRO DE GEOGRAFIA E ESTATÍSTICA. Recenseamento Geral do Brasil. Serviço Gráfico do Instituto Brasileiro de Geografia e Estatística, 1950. P. 29.

MICELI, Sérgio. Intelectuais e classe dirigente no Brasil (1920-1945). São Paulo - Rio de Janeiro: Difel/Difusão Editorial S.A. 1979.

MARCONDES FILHO, Alexandre. Trabalhadores do Brasil. Rio de Janeiro: Edição da Revista Judiciária, 1943

NORA, Pierra. Entre memória e história: a problemática dos lugares. Projeto História, São Paulo, PUC, nº 10, dez. 1993.

OLIVEIRA, Lúcia Lippi. O intelectual do DIP: Lourival Fontes e o Estado Novo. In.

Constelação Capanema: intelectuais e política. Helena Bomeny (Org.). Rio de Janeiro: Ed. Fundação Getulio Vargas; Bragança Paulista (SP): Ed. Universidade de São Francisco, 2001.

POLETTI, Ronaldo. Constituições Brasileiras: 1934. $3^{\mathrm{a}}$ ed. Brasília: Senado Federal/Subsecretaria de Edições Técnicas, 2012. 
PONTES JR, Geraldo. PEREIRA, Victor Hugo Adler (orgs.). O velho, o novo, o reciclável Estado Novo. Rio de Janeiro: De Letras, 2008.

SEIXAS, Jacy Alves de. Percursos e memórias em terras de história: problemáticas atuais. In. BRESCIANI, Stella; NAXARA, Marcia. Memória e (res)sentimentos. Indagações sobre uma questão sensível. Ed. UNICAMP. 2004.

SILVEIRA, Helder Gordim da. ABREU, Luciano Aronne de. (orgs). De Vargas aos militares: autoritarismo e desenvolvimento econômico no Brasil. Porto Alegre: Edipucrs, 2014.

SIRONNEAU, Jean-Pierre. Retorno do mito e imaginário sócio-político e organizacional. Revista da Faculdade de Educação. São Paulo, nº 11, p. 243-274, 1985.

VARGAS, Getúlio. A nova política do Brasil: O Estado Novo [de] 10 de novembro de 1937 a 25 de julho 1938. Rio de Janeiro: José Olympio, 1938. V. 5.

. A nova política do Brasil: No limiar de uma nova era [de] 20 de outubro de 1939 a 29 de junho de 1940. Rio de Janeiro: José Olympio, 1940. V. 7.

VELLOSO, Mônica Pimenta. "Uma Configuração do Campo Intelectual”. In: OLIVEIRA, Lúcia Lippi; VELLOSO, Mônica Pimenta \& GOMES, Ângela Maria de Castro (Orgs.).

Estado Novo: Ideologia e Poder. Rio de Janeiro: Zahar Editores, 1982.

WINTER, Jay. A geração da memória: reflexões sobre o "boom da memória" nos estudos contemporâneos de história. In: SELLIGMAN-SILVA, Márcio (org.). Palavra e imagem: memória e escritura. Chapecó, SC: Argos, 2006. 